\title{
Mazzaropi e Lobato: Jeca Tatu ainda dá umas boas horas de conversa e pesquisa
}

Maria Ignês Carlos Magno

Doutora em Ciências da Comunicaşão pela ECA/USP.

Professora do Mestrado em Comunicação da Universidade Anhembi Morumbi

e da Fundação Escola de Sociologia e Política de São Paulo.

E-mail: unsigster@gmail.com

Resumo: Nesta edição, é apresentada uma releitura de Monteiro Lobato e sua personagem Jeca Tatu e o cinema de Amácio Mazzaropi, propondo o filme Jeca Tatu como ponto de partida para alguns estudos sobre o Brasil e nossa produção cultural.

Palavras-chave: literatura, cinema, cultura, educação, publicidade.
Abstract: In this edition, it is presented a reinterpretation of Monteiro Lobato and his character Jeca Tatu, and the cinema of Amácio Mazzaropi. The motion picture Jeca Tatu is proposed as starting point to some studies on Brazil and our cultural production.

Keywords: literature, cinema, culture, education, advertising
Jeca Total deve ser Jeca Tatu

Presente, passado

Representante da gente no Senado

Em plena sessão

Defendendo um projeto

Que eleva o teto

Salarial no sertão.

Jeca Total deve ser Jeca Tatu

Doente curado

Representante da gente na sala

Defronte da televisão

Assistindo Gabriela

Viver tantas cores

Dores da emancipação.

Jeca Total deve ser Jeca Tatu.

Um ente querido

Representante da gente no Olimpo

Da imaginação

Imaginacionando o que seria a criação
De um ditado

Dito popular

Mito da mitologia brasileira

Jeca Total.

Jeca Total deve ser Jeca Tatu

Um tempo perdido

Interessante a maneira do tempo

Ter perdição

Quer dizer, se perder no correr

Decorrer da história

Glória, decadência, memória

Era de Aquarius

Ou mera ilusão.

Jeca Total deve ser Jeca Tatu

Jorge Salomão

Jeca Total Jeca Tatu Jeca Total Jeca Tatu Jeca Tatu Jeca Total Jeca Tatu Jeca Total.

(Gilberto Gil) 
comunicação \& educação • Ano XIII • Número 3 • set/dez 2008

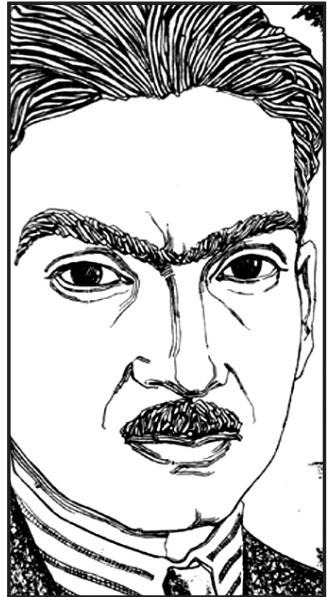

O título pode causar estranheza, afinal, diante de tantos filmes e personagens novos no atual cenário cinematográfico que poderiam ser indicados nesta seção, por que Monteiro Lobato, sua personagem Jeca Tatu e o cinema de Amácio Mazzaropi? Tudo tão arcaico e deslocado nestes tempos hipermodernos... Lobato, talvez, porque o Jeca, em suas diversas faces e fases, pode nos mostrar as histórias que permeiam o arcaico e o moderno nas histórias do Brasil. Mazzaropi porque, ao eternizar uma figura do caipira brasileiro nas telas de cinema e no imaginário de uma época, possibilita pensar essa personagem na cultura brasileira, bem como as representações que seus filmes fizeram desse tipo. Especialmente, porque trouxeram para os meios de comunicação uma personagem que tem as marcas de um Brasil que desde suas origens se vê às voltas com discursos modernos dentro de arcaicas estruturas. Ambos os artistas porque, a despeito de toda popularidade que seus personagens e filmes tiveram, suscitaram debates nos meios acadêmicos e especializados.

Apesar da estranheza, pensando no filme como possibilidade de reler Lobato, rever ou mesmo conhecer o cinema de Mazzaropi, e também porque na figura do Jeca o Brasil passou a ser uma personagem a ser decifrada em suas muitas e polêmicas faces, proponho o filme Jeca Tatu, de Amácio Mazzaropi, como ponto de partida para alguns estudos sobre o Brasil e nossa produção cultural.

\section{FICHA TÉCNICA}

Título original - Jeca Tatu

Gênero - comédia

Duração - 95 min.

Lançamento (Brasil) - 1959

Distribuição - Unida Filmes

Direção - Milton Amaral

Roteiro - Milton Amaral

Argumento - Amácio Mazzaropi

Produção - PAM Filmes

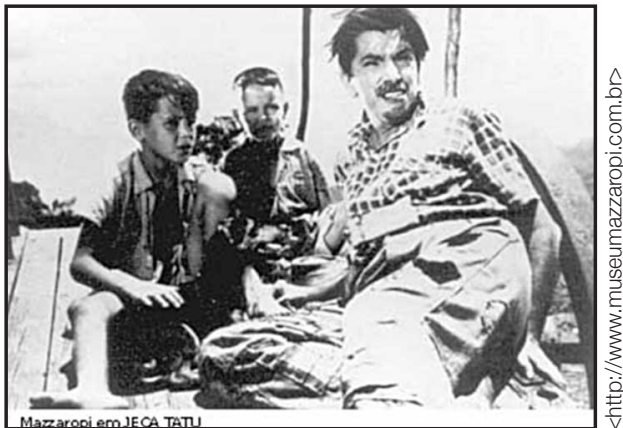


Diretor de produção - Felix Aidar

Música - Hector Lagna Fietta

Fotografia - Rodolfo Icsey

Câmera - George Pfister

Foco - Marcial Alfonso

Assistente de fotografia - Hector Femenia

Fotógrafo de cena - José Amaral

Engenheiro de som - Ernest Hack

e Constantino Warnowsky

Continuista - José Soares

Edição - Mauro Alice

\section{SOBRE O JECA TATU DE LOBATO E O DE MAZZAROPI: ALGUMAS HISTÓRIAS}

Entre o Jeca Tatu criado por Monteiro Lobato, em 1914, e a personagem de Mazzaropi, levado às telas em 1959, muitas histórias podem ser recuperadas. No entanto, a história que ficou gravada no imaginário popular foi a do Jeca Tatuzinho, escrita em 1924 para ensinar noções de higiene e saneamento às crianças e adaptada em 1925 para compor o

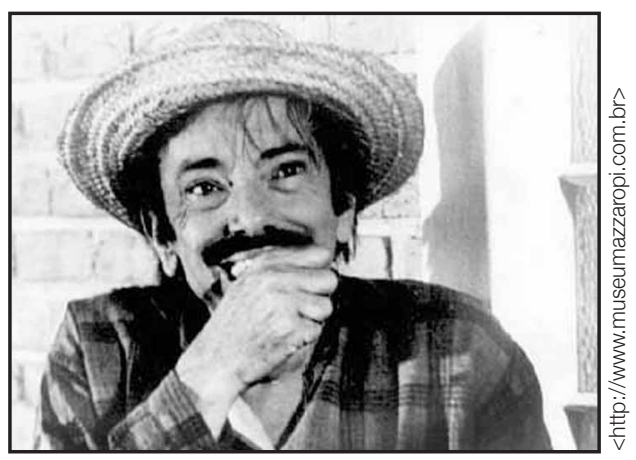
folheto publicitário do Biotônico Fontoura. O personagem-símbolo aparecia assim descrito na primeira das dezoito partes da história:

Jeca Tatu era um pobre caboclo que morava no mato, numa casinha de sapé. Vivia na maior pobreza, em companhia da mulher, muito magra e feia, e de vários filhinhos pálidos e tristes. Jeca Tatu passava os dias de cócoras, pitando enormes cigarrões de palha, sem ânimo de fazer coisa alguma. Ia ao mato caçar, tirar palmitos, cortar cachos de brejaúva, mas não tinha idéia de plantar um pé de couve atrás da casa. Perto corria um ribeirão, onde ele pescava de vez em quando uns lambaris e um ou outro bagre. E assim ia vivendo. Dava pena ver a miséria do casebre. Nem móveis, nem roupas, nem nada que significasse comodidade. Um banquinho de três pernas, umas peneiras furadas, a espingardinha de carregar pela boca, muito ordinária, e só. Todos que passavam por ali murmuravam: "Que grandessíssimo preguiçoso!"?.

Tanto Lobato como Mazzaropi têm com o caipira, especialmente com Jeca Tatu, uma história particular. De acordo com a escritora Marisa Lajolo a história do Jeca Tatu está diretamente ligada com a biografia de Monteiro Lobato, que herdou de seu avô a fazenda Buquira, no Vale do Paraíba, em São Paulo, e se tornou um fazendeiro cheio de idéias contemporâneas. Uma delas, a de modernizar a agricultura e a pecuária. No entanto, ao assumir a fazenda

2. Disponível em <http:// www.brasilcultura.com. br/conteudo.php?menu= $95 \& i d=452 \&$ sub $=490>$. Acesso em: 23 jun. 2008.

3. Disponível em: <http:// www.comciencia.br/entrevistas/2005/06/entrevista1.htm>. Acesso em: 23 jun. 2008. 
comunicação \& educação • Ano XIII • Número 3 • set/dez 2008

4. LAJOLO, Marisa. Jeca Tatu mostra um Monteiro Lobato preocupado com a saúde pública. Entrevista. Disponível em: $<$ http://www.comciencia. br/entrevistas/2005/06/ entrevista1.htm>, p. 2.

5. Ibid., p. 2.

6. GOMES, Mario Luiz. Vendendo saúde! Revisitando os antigos almanaques de farmácia. História, Ciência e Saúde - Manguinhos, Rio de Janeiro, v. 13, n. 4 , out./ dez. 2006. e querer modernizar as estruturas encontradas, deparou-se com as práticas arraigadas do camponês. Das brigas e desentendimentos, escreveu uma carta para o jornal $O$ Estado de $S$. Paulo em que "cria uma figura desqualificada (que viria a ser o Jeca Tatu) para representar o caipira". Nas cartas enviadas ao jornal, Lobato atribui ao trabalhador rural, ao camponês, a responsabilidade pelos problemas da agricultura. Sua visão é a de que eram preguiçosos demais para mudar tanto a agricultura como seu próprio mundo. Nesse momento, continua Lajolo, "Lobato é implacável na desqualificação de toda cultura caipira, de suas manifestações artísticas à sua linguagem e às suas práticas econômicas"

É interessante observar as relações entre autor e personagem, e estes ligados a um contexto histórico e sociológico. Se recuperarmos as transformações que ocorriam no cenário da história brasileira desde o final dos anos de 1890, em especial as campanhas sanitaristas empreendidas a partir de 1904, tendo à frente o médico e pesquisador Oswaldo Cruz, é fácil compreendermos as contradições internas do país e as mudanças que Lobato imprimiu a sua personagem. De responsável pelo atraso e pela estagnação do Brasil agrário, torna-se uma das vítimas da precariedade da saúde pública, dos vermes e das epidemias que se alastravam em todo o território. É nesse momento que Lobato, ao mesmo tempo em que se envolve totalmente em campanhas de saúde contra as doenças tropicais, cria o Jeca Tatuzinho para ensinar noções de saúde e saneamento às crianças. Aqui também cabem duas observações: nas suas primeiras campanhas de saúde, a preocupação estava em ensinar os hábitos necessários para uma boa saúde, como andar de botas, lavar as mãos e tomar a erva-de-santa-maria como vermífugo, e as mudanças provocadas nos textos a partir de suas relações com a indústria farmacêutica.

\section{A PROPAGANDA IMPRESSA NO ALMANAQUE}

Lobato foi o idealizador e o responsável pela criação do exemplar inaugural do Almanach Biotônico, em 1920. Parte da campanha contra a verminose trazia a divulgação da Ankilostomina e do próprio Biotônico Fontoura ${ }^{6}$. O sucesso foi tanto que Lobato passou a ser considerado "o intelectual mais importante para a história da propaganda nos almanaques de farmácia”? Ligado às tradições culturais de uma medicina popular ou à indústria farmacêutica, o interessante é sabermos que, além de Lobato ter-se mantido nas campanhas pela saúde pública, se envolveu em outras como a do Petróleo, por exemplo, e durante os

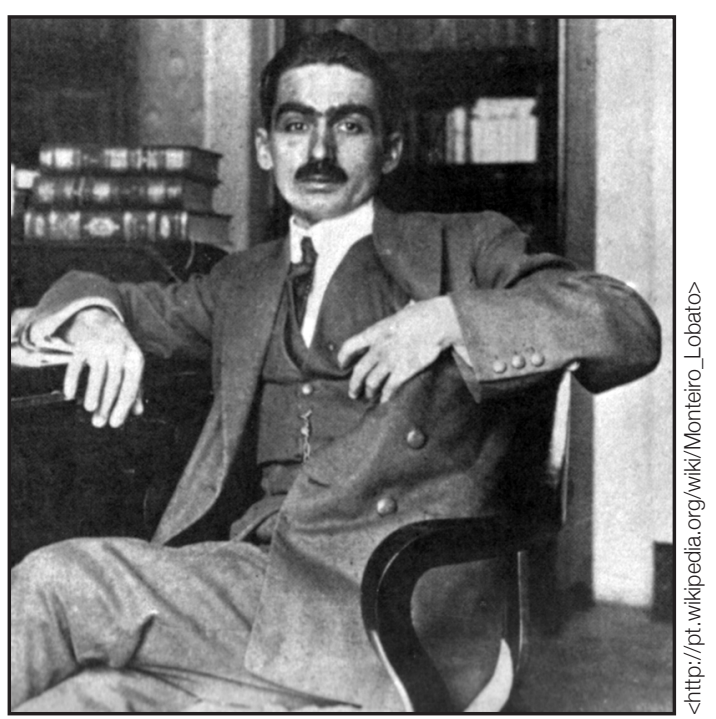




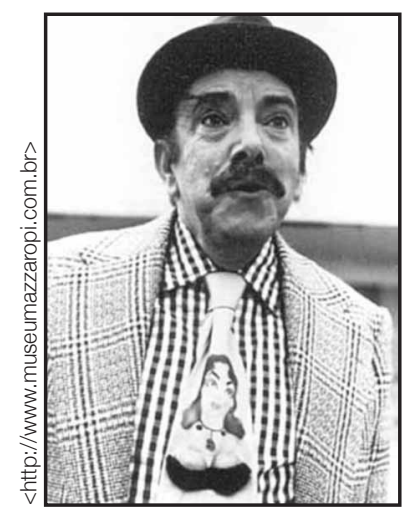

anos de 1940 seu personagem sofre uma terceira leitura e representação. Em 1936, ao escrever O Escândalo do Petróleo, acusando o governo de não perfurar e não deixar que se perfure, teve os exemplares do livro recolhidos pelo Estado. Na tentativa de trazê-lo para perto de si, Getúlio Vargas convida-o para dirigir o Ministério de Propaganda. Lobato recusa o convite e faz duras críticas à política de minérios, as quais são consideradas subversivas. Foi detido pela polícia do Estado Novo e condenado a seis meses de prisão. Libertado três meses depois com apoio de amigos e intelectuais que promoveram um movimento junto a Getúlio, passou a ser perseguido pela polícia política do Estado Novo, fato que levou Lobato a denunciar as torturas praticadas contra os presos políticos ${ }^{8}$. Finalmente, nos anos 1940, ele cria Zé Brasil e se aproxima cada vez mais da cultura caipira,

[...] articulando-a a questões econômicas: o Jeca - agora rebatizado de Zé Brasil, numa renomeação bastante sugestiva - é pouco produtivo porque não é dono da terra em que trabalha. Ou seja, o Jeca não é preguiçoso, nem doente, mas sim vítima do latifúndio brasileiro' ${ }^{9}$.

O Jeca Tatu de Mazzaropi foi, segundo o ator e diretor, uma homenagem ao personagem de Monteiro Lobato. É bem verdade que a construção de seu caipira nasceu antes do filme Jeca Tatu. Veio do gosto pela vida do campo, herdado de seu avô Amácio Mazzaropi, um imigrante italiano que se fixou nas terras paranaenses. Foi essa afeição pelo campo que o levou a pesquisar no interior do Brasil o personagem de calças curtas, canelas descobertas, botinas, fala arrastada, e que fez nascer o caipira Mazzaropi. Outra influência foi a do circo e das peças que eram apresentadas e que tinham no caipira a figura que fazia sucesso. Gostava de dois atores: Genésio e Sebastião. Mas, conta Mazzaropi, seu preferido era Sebastião de Arruda, por não ser tão caricato como Genésio. No começo de sua carreira, disse ter tentado imitar Sebastião em sua naturalidade, mas, depois, foi para o interior para criar seu próprio tipo: o caboclão bastante natural, na roupa, no andar, no falar. "Um simples caboclo entre milhões que vivem no interior do Brasil". Ainda sobre a criação de sua personagem caipira, comentou:

Saí pro interior um pouco Sebastião, voltei Mazzaropi. Não mudei meu nome (embora tivessem cansado de me aconselhar a mudá-lo) por não haver mal nenhum naquilo que eu ia fazer. Os amigos diziam que Mazzaropi não era nome de caipira, que era nome de italiano, mas eu respondia para eles que, se não era, iria virar. Que eu não tinha vergonha do que ia fazer e, por isso, ia fazer com meu nome. E o público gostou do meu nome, gostou do que eu fiz. Turnês em circos, teatros, recitando monólogos dramáticos, fazendo a platéia rir, $\operatorname{chorar}^{10}$.

Como caipira, foi motorista, jardineiro, vendedor de lingüiça, trabalhador no zoológico, chefe da carrocinha, sapateiro, engraxate, entre tantas profissões
7. Ibid.

8. Disponível em: <http:// pt.wikipedia.org/wiki/ Monteiro_Lobato>.

9. LAJOLO, Marisa. Jeca Tatu mostra um Monteiro Lobato preocupado com a saúde pública. Entrevista. Disponivel em: $<$ http://www.comciencia. br/entrevistas/2005/06/ entrevista1.htm>, p. 2.

10. Disponível em: <http://www.museumazzaropi.com.br/int_hist. $h t m>$. 
comunicação \& educação • Ano XIII • Número 3 • set/dez 2008

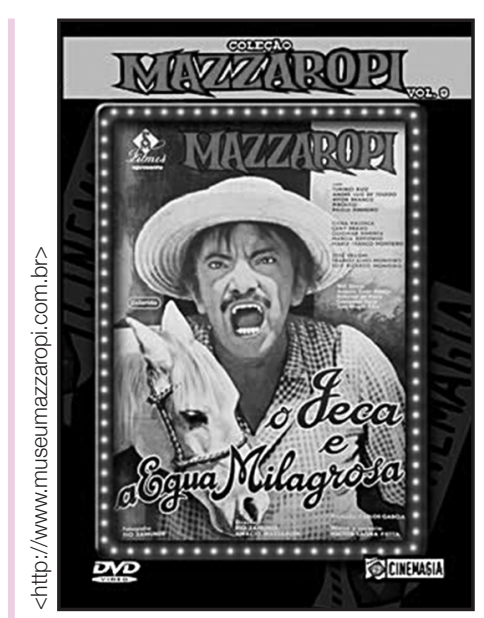

de gente simples e, na sua maioria, migrantes do interior para a cidade grande, fato que o aproximou bastante das platéias. Mas foi como Jeca, filme de 1959, que conseguiu completar o tipo e entrar no universo da cultura caipira. Da personagem original de Lobato, Mazzaropi manteve quase tudo: caboclo pobre e preguiçoso, mas de bom coração. Retirou, no entanto, o vício da bebida e acrescentou-lhe a astúcia. Mazzaropi, como Jeca Tatu, fez Tristeza do Jeca; O Jeca e a Freira; Uma Pistola para Djeca; Jeca, o Macumbeiro; Jeca Contra o Capeta; Jeca, um Fofoqueiro no Céu; Jeca e Seu Filho Preto e Jeca e a Égua Milagrosa.

Nos tempos de Lobato, o Brasil de Mazzaropi vivia, nos anos de 1950, como a maioria dos países, a euforia do crescimento e do desenvolvimento pós-guerra. E novamente a idéia de modernização do país estava na pauta do dia. De novo, a luta entre o arcaico e o moderno estava na ordem da história.

E na dança da história da década de 1950, o que vemos, num primeiro olhar, é um baile projetado sob o teto ideológico do desenvolvimentismo e da urgência de tornar o Brasil um país moderno, nem que para isso, e precisamente por isso, fosse necessário esquecer, esconder aspectos políticos e sociais, ou transformar em folclore outras histórias que, aprisionadas por regionalismos ou minimizadas em sua importância, pareciam não fazer parte de uma história maior que era a da construção de uma nação forte no contexto da modernidade capitalista. Daí, também, a necessidade de negar outros projetos e espaços de desenvolvimento e formas de lutas ou projetos que não aqueles que participavam diretamente do pacto econômico-político estabelecidos pela burguesia urbana e pela política do poder central; nesse caso, a negação das lutas camponesas que foram intensas e de uma complexidade desconhecida durante toda a década de 1950 até meados dos anos de 1960, quando o Golpe militar se encarregou de seu extermínio.

Sob a ideologia do desenvolvimentismo, o campo foi negado em sua existência, traduzido como espaço de atraso econômico, e o camponês visto como um analfabeto político e cultural, como alguém que "participa como se não fosse essencial, como se não estivesse participando; como incapazes de fazer história, de definir e atuar no processo histórico, que o camponês foi colocado no debate político"11. Se o lugar do camponês no processo histórico era pautado pela exclusão, e suas guerras, desde 1896, com Canudos, e 1912, com o Contestado, eram vistas como movimentos de fanáticos e rebeldes, o que nos escapa é o fato de que todas as suas lutas tiveram como ponto central as disputas pela terra e

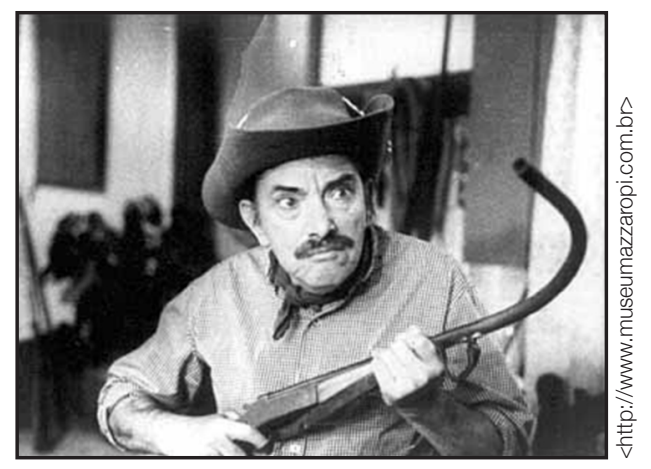

11. MARTINS, Jose de Sousa. Os camponese e a política no Brasil. Petrópolis: Vozes, 1986. p. 67-68. 


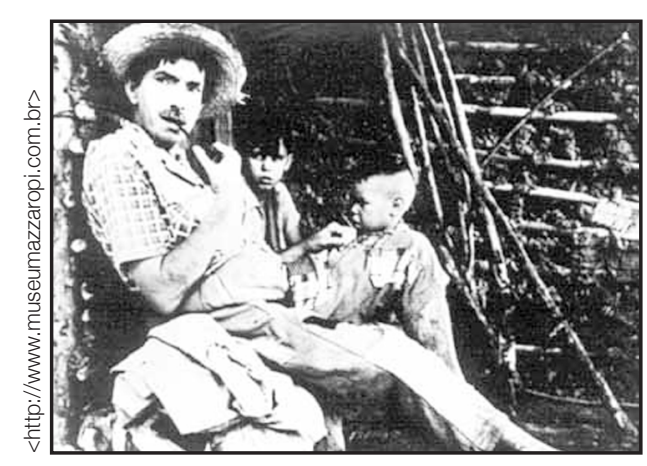

pela renda desta, além de que, a exclusão fazia parte de "uma nova forma de dominação do capital e de apropriação das terras sob outros interesses" ${ }^{\prime 2}$. A título de exemplos, basta retomarmos os anos de 1945/1948, quando se deu o início das expulsões dos camponeses de suas terras e o começo de uma peregrinação sem fim na história até os dias atuais.

No entanto, mesmo aprisionados nos regionalismos, ocultados enquanto formas vivas de lutas ou transformados em exóticos movimentos pré-políticos, aqueles fanáticos, cangaceiros e incultos camponeses retornaram, durante os anos de 1960, aos bancos universitários, à produção literária, às telas de cinema. É preciso considerar que, se de um lado, existia a necessidade de "obscurecer para propiciar uma identificação mais fácil com a modernidade, por outro, o mecanismo ideológico da negação"13 não conduziu àquela consciência moderna pretendida, mas a um questionamento de tais movimentos e lutas, uma vez que a questão da terra era um dos problemas cruciais para o Estado e para o capital, tanto nacional como estrangeiro. Nesse sentido, muitos foram os estudos suscitados e as formas de representação ficcionais produzidas.

Como o intuito é mostrar como os aspectos da realidade são elaborados na produção ficcional, torna-se interessante ressaltar que a produção cinematográfica que tratava do camponês ou do caipira brasileiro se concentrou entre os anos de 1963/1964, período em que o desejo de uma revolução social, ao mesmo tempo em que deflagrava uma crítica ao modelo político-cultural anteriormente apresentado, propunha uma retomada de temas, épocas e lutas que favorecessem as discussões em torno dos problemas brasileiros e levassem a uma conscientização da realidade vivenciada. Nesta direção, o jogo entre o esconder e o mostrar aspectos conflitantes no terreno da história pode ser apreendido nos discursos, nos projetos políticos, nos ensaios sociológicos, nas produções culturais.

Neste ponto uma diferença entre autores e representações. Enquanto o Jeca Tatu de Lobato esteve sempre engajado em campanhas referentes aos problemas do Brasil, o cinema caipira e o Jeca de Mazzaropi, embora falassem dos mesmos temas e tivessem nas disputas de terras, nos mandos e desmandos de coronéis um de seus focos, trazia-os sob a forma de comédia e sem preocupações com mudanças sociais, como podemos acompanhar na crítica de Jean-Claude Bernardet:

Está aí o cinema de Mazzaropi atraindo multidões, as multidões que se identificam com os problemas colocados na tela: o trabalhador oprimido, as relações marido-mulher, pais e filhos,

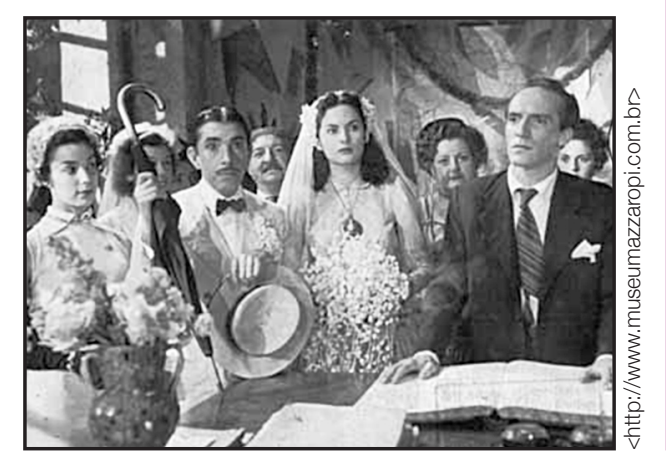

12. Ibid., p. 25.

13. DORIA, Carlos Alberto. Ensaios enveredados. São Paulo: Siciliano, 1991. p. $15-16$. 
religião, etc. Jeca e Seu Filho Preto, seu último lançamento, aborda o problema do racismo e o alia às diferenças sociais e culturais; mas esvazia a questão quando o racismo vira consangüinidade a impedir um casório. Mazzaropi fica assim: joga questões, tempera com humor, e o público ri até das impossibilidades de resolver qualquer coisa $^{14}$.

Essa caracterísitca de sua produção, entre outros aspectos, explicava por que seus filmes, mesmo batendo recordes de bilheterias, não alcançassem entre intelectuais e especialistas uma boa aceitação e as críticas fossem, na sua maioria, desfavoráveis. Na crítica de Ignácio de Loyola escrita para o jornal Última Hora, em 4 de fevereiro de 1965, na seção Cine-Ronda, sob o título A Contribuição de Mazzaropi para o Retrocesso, escreveu:

Nosso povo vive dentro de um estágio cultural condicionado pelo subdesenvolvimento. Sob tal condição, é natural que a exaltação da mediocridade vingue. Compreende-se que o homem do povo aceite, até por desfastio, o cinema banal, vulgar, incipiente, imbecil. Falta-lhe, além de um gosto apurado, a oportunidade de conhecer obras superiores.

Todavia, quando um homem tido como de cultura, tendo em suas mãos um instrumento de divulgação, senta-se numa poltrona de cinema e aprecia o vulgarismo, a imbecilidade, o primarismo (e ainda recomenda como de alto teor), então, é a mediocridade, é o andar para trás. [...] O filme vem rendendo fábulas e o Cine Art-Palácio o colocou em segunda semana, pela primeira vez nos últimos dez anos. [...] Uma vez dissemos aqui que a linha de comédias do Mazzaropi era aceitável. Não deixa de ser um gênero que tem seu público. Não contávamos, todavia, com a inexistência, em Mazzaropi, do fator evolução, natural no artista (caberia aqui uma discussão estéril, a fim de saber se Mazza é artista ou não. Deixemos pra lá!). Bitolado, fora de época, ausente de tudo que se passa ao seu redor, a Mazzaropi interessa apenas explorar e fomentar o gosto equívoco, não possuindo o cinema, para ele, qualquer implicação cultural ${ }^{15}$.

No entanto, se aprofundarmos essa discussão encontraremos, além da mágoa que Mazzaropi tinha da crítica, a sua posição sobre cinema nacional e indústria. Em resposta a uma das perguntas feitas por Armando Salem em entrevista dada à revista Veja de janeiro de 1970, declarou:

Não, não tenho sócio. Tenho o necessário para pensar em fazer amanhã ou depois a indústria cinematográfica de que falei. Tenho câmeras de filmar, holofotes, lâmpadas, cavalos, cenários, agências em São Paulo, Rio, Norte do país, e uma fazenda de 184 alqueires no Vale do Paraíba - Taubaté - que serve perfeitamente de estúdio para os filmes que rodo. Como vê, tudo que ganho é aplicado na Pam-Filmes, no cinema brasileiro. E depois vêm esses críticos de cinema metidos a intelectuais dizendo: "O Mazzaropi tá cheio de dinheiro. Ele tá podre de rico. Não sabe onde pôr o dinheiro". Não são capazes de entender que eu faço cinema como indústria. E o cinema é uma indústria como qualquer outra. Eu faço o cinema-indústria e vou fazer a indústria brasileira de cinema ${ }^{16}$.

Lobato, como Mazzaropi, também foi visto como reacionário após a publicação do artigo Paranóia ou Mistificação, em que criticava a exposição de Anita Malfatti. Se a discussão era contra tantos ismos europeus ou não, a verdade é 
que o artigo deu o que falar. Hoje, se a idéia é a de que Lobato era a favor de uma arte brasileira, e produzida aqui dentro mesmo, é também conhecido o fato de que o lado empresarial sempre o acompanhou. Basta lembrarmos que criou sua própria editora, a Monteiro Lobato $\mathcal{E}$ Cia, bem como uma rede nacional de distribuição de seus livros. Mazzaropi pensava em um cinema nacional e acreditava que era possível produzir uma grande indústria cinematográfica brasileira. Idéias que podem ser apreendidas no depoimento exclusivo dado a Caco Barcelos, O Jeca Contra o Tubarão, quando inicia seu depoimento perguntando: "Viram o Tubarão? Me dá vontade de dar um soco nos beiços do bonecão quando ele aparece com aqueles dentão na tela. Por que nós não fizemos para o dinheiro ficar aqui mesmo?"17.

Finalizando estas poucas histórias sobre Jecas em um Brasil que oscila entre o moderno e o arcaico, vale a pena recuperar dois outros textos sobre a obra e as personagens em Lobato e Mazzaropi. Em O Jeca Tatu de Monteiro Lobato, o poeta de cordel Walter Medeiros escreveu:

Porém, Monteiro Lobato,

Esse genial escritor,

Já fazia suas críticas

A todo historiador

Que maquia personagens

E lhes dá falso valor ${ }^{18}$.

E um pequeno trecho da crítica de Paulo Emílio Salles Gomes, citado por Caco Barcelos em O Jeca Contra o Tubarão:

Mazzaropi atinge o arcaico da sociedade brasileira e de cada em de nós. Um inverso da redundância. Ele é estimulante quando repete e se repete incansavelmente e sem nos cansar. De tanto repetir, de repente, uma inesperada poesia. Sucede quando ele não está fazendo nada de especial, apenas olhando, andando ou pondo o fumo no pito ${ }^{19}$.

\section{PARA PESQUISAR E CONVERSAR SOBRE O BRASIL E A CULTURA BRASILEIRA}

Jeca Tatu é sempre uma personagem que nos vem à mente quando pensamos o Brasil e a cultura brasileira. Às vezes como referência para debates críticos, outras como melancolia de tipos que aos poucos foram se extinguindo diante das transformações ocorridas ao longo de nossa história. O bom é que sempre que retornamos às origens, e continuamente retornamos com propósitos diferentes, o que encontramos é quase sempre o inesperado. Lobato, Mazzaropi e Jeca Tatu, de uns tempos para cá, têm me visitado com freqüência nesta época de intensos debates sobre culturas, mundializações, retornos, identidades, lugares da cultura, entre outros temas e fatos contemporâneos. Lobato, em especial, por suas investidas em temáticas que, se não foram lidas e pensadas naquele momento, hoje, merecem, pelo menos, uma re-leitura para rever os argumentos. Falo das obras: O Presidente Negro e O Escândalo do Petróleo. Jeca Tatu,
17. Disponível em: $<$ http://www.museumazzaropi.com.br/sucesso/ suc07.htm>.

18. MEDEIROS, Walter. O Jeca Tatu de Monteiro Lobato. In: Poemas de Cordel. Disponível em: <http://paginas.terra.com.br/arte/cordel/ ap031jeca.htm>. Acesso em: 10 jul. 2008.

19. Disponível em: <http://www.museumazzaropi.com.br/sucesso/ suc07.htm>. 
comunicação \& educação • Ano XIII • Número 3 • set/dez 2008

em especial, porque, novamente, Parceiros do Rio Bonito, de Antonio Candido ${ }^{20}$, voltou a ser uma das leituras obrigatórias para entendermos as mudanças ocorridas com a cultura do caipira, em especial a do caipira paulista a partir de 1960/1970. Mazzaropi nesse bloco parece destoar, mas se observarmos nas bancas clandestinas e legais, e gôndolas de supermercados, o volume de pessoas que procuram por seus filmes, desfaz-se essa impressão. Mesmo os mais jovens, que nunca assistiram a um filme seu, sabem que seus avós gostavam dele. Outro fato é que seus filmes estão sendo retomados e estudados por pesquisadores do cinema brasileiro. Estes foram alguns dos motivos que me levaram a propor, para esta Videografia, o filme Jeca Tatu como ponto de partida para pesquisas e conversações sobre o Brasil em diferentes tempos e dilemas.

Que as questões agrárias e de saúde pública no Brasil beiram à ficção científica, já sabemos. Que a cultura caipira está em vias de desaparecimento, podemos prever. Que as obras literárias sempre inspiraram o cinema, também é fato. O que quase nunca fazemos é analisarmos como o Brasil, seus problemas e produções culturais, podem ser o elemento-chave de descobertas e de conhecimentos. Nesta perspectiva, sugiro, como fio condutor de um projeto interdisciplinar, o trabalho com a obra de Monteiro Lobato e de Mazzaropi.

\section{REFERÊNCIAS BIBLIOGRÁFICAS}

DORIA, Carlos Alberto. Ensaios enveredados. São Paulo: Siciliano, 1991.

GOMES, Mario Luiz. Vendendo saúde! Revisitando os antigos almanaques de farmácia. História, Ciência e Saúde - Manguinhos, Rio de Janeiro, v. 13, n. 4, out./dez. 2006.

MARTINS, José de Sousa. Os camponeses e a política no Brasil. Petrópolis: Vozes, 1986.

\section{Endereços eletrônicos}

$<$ http:/ / www.brasilcultura.com.br/conteudo.php?menu=95\&id=452\&sub=490>.

$<$ http://www.comciencia.br/entrevistas/2005/06/entrevista1.htm>.

$<$ http://pt.wikipedia.org/wiki/Monteiro_Lobato $>$.

$<$ http://www.museumazzaropi.com.br/int_hist.htm>.

$<$ http://www.museumazzaropi.com.br/sucesso/suc11.htm>.

$<$ http://www.museumazzaropi.com.br/sucesso/suc03.htm>.

Par. Antonio.

9. ed. São Paulo: Editora

34/Livraria duas cidades, 2001.

$<$ http://www.museumazzaropi.com.br/sucesso/suc07.htm>.

$<$ http://paginas.terra.com.br/arte/cordel/ap031jeca.htm>. 